\title{
Use of androgen deprivation therapy in prostate cancer: indications and prevalence
}

\author{
Roisin M Connolly, Michael A Carducci and Emmanuel S Antonarakis
}

\begin{abstract}
Androgens play a prominent role in the development, maintenance and progression of prostate cancer. The introduction of androgen deprivation therapies into the treatment paradigm for prostate cancer patients has resulted in a wide variety of benefits ranging from a survival advantage for those with clinically localized or locally advanced disease, to improvements in symptom control for patients with advanced disease. Controversies remain, however, surrounding the optimal timing, duration and schedule of these hormonal approaches. Newer hormonal manipulations such as abiraterone acetate have also been investigated and will broaden treatment options for men with prostate cancer. This review highlights the various androgen-directed treatment options available to men with prostate cancer, their specific indications and the evidence supporting each approach, as well as patterns of use of hormonal therapies. Asian Journal of Andrology (2012) 14, 177-186; doi:10.1038/aja.2011.103; published online 9 January 2012
\end{abstract}

Keywords: androgen deprivation therapy; androgen synthesis; anti-androgen; prostate cancer

\section{INTRODUCTION}

Prostate cancer is the most common non-cutaneous malignancy in men in the United States of America and worldwide, and the second leading cause of cancer death. The median age at diagnosis is approximately 67 years. It is estimated that 240890 men will be diagnosed with prostate cancer and 33720 men will die of the disease in 2011 in the United States of America. ${ }^{1}$ Despite the prevalence of prostate cancer, the 5-year relative survival for men with localized or locally advanced disease is excellent at almost $100 \% .^{1}$ With the introduction of prostate-specific antigen (PSA) screening, most men in the present era are diagnosed as having localized disease, and only a small percentage $(<10 \%)$ have locally advanced or metastatic disease at initial diagnosis. Unfortunately, men with metastatic disease have a 5-year relative survival of only about $30 \% .{ }^{1}$ The use of androgen deprivation therapy (ADT) has improved symptom control for patients with metastatic prostate cancer, but no survival advantage has been conclusively demonstrated in these patients. ${ }^{2}$ By contrast, the addition of ADT to primary external beam radiation therapy (RT) has been shown to improve survival in intermediate- and high-risk patients with localized disease and patients with locally advanced disease. The rationale for use of ADT in prostate cancer as well as the data supporting its use in various prostate cancer settings will be reviewed.

\section{ANDROGEN BIOSYNTHESIS}

The hypothalamus secretes gonadotropin-releasing hormone ( $\mathrm{GnRH})$ in a pulsatile fashion, which in turn acts on the anterior pituitary gland to cause pulsatile release of the gonadotropins, luteinizing hormone ( $\mathrm{LH})$ and follicle-stimulating hormone $(\mathrm{FSH}){ }^{3}{ }^{3} \mathrm{LH}$ targets the testicular Leydig cell receptors, thereby promoting the synthesis of testosterone. ${ }^{4}$ FSH interacts with the testicular Sertoli cells to promote the conversion of testosterone to estrogen. ${ }^{5}$ Testosterone itself is synthesized in the testes (approximately 90\%) and adrenal glands from its precursor steroid, cholesterol, via a number of enzymatic steps. It is subsequently converted in peripheral tissues to its active metabolites dihydrotestosterone (DHT) and estradiol by $5 \alpha$-reductase and aromatase respectively (Figure 1). ${ }^{6}$ DHT has a high affinity for the androgen receptor and along with testosterone itself, mediates the major functions of androgens including regulation of gonadotropin signaling, spermatogenesis and sexual maturation. Because androgens are responsible for the initiation, maintenance and progression of prostate cancer, strategies which block testosterone production or action have been established as therapeutic strategies in patients with this disease. Continuous administration of GnRH or its analogs inhibits LH and FSH release and therefore androgen levels, and represents an approved method of androgen deprivation for use in prostate cancer.

\section{ADT}

ADT refers to any intervention which results in the androgen receptor of target cells not being activated via either a reduction in the production of testosterone or blockade of the androgen receptor. This treatment approach is achieved by both surgical and medical castration, anti-androgen therapies, and any combinations of these (Table 1).

\section{Surgical vs. medical castration}

The aim of castration is to lower serum testosterone to $<50 \mathrm{ng} \mathrm{dl}{ }^{-1}$ such that the stimulation of prostate cancer cells is minimized. In clinical practice, levels $<20 \mathrm{ng} \mathrm{dl}^{-1}$ are usually reached. Surgical castration by bilateral orchiectomy has been recognized as an effective method of rapidly decreasing testosterone levels since the 1940 s. $^{7}$ The Veterans Affairs Research Service Cooperative Urological Research 


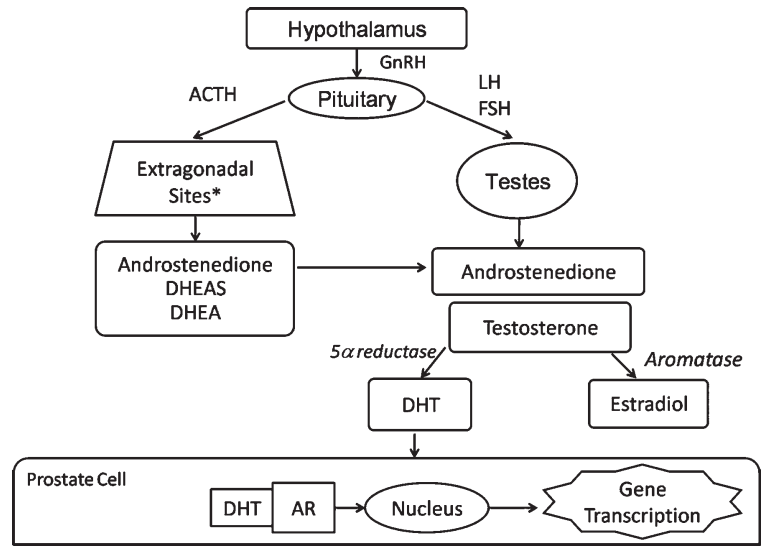

Figure 1 Androgen biosynthesis pathways. *Adrenal gland, prostate gland, intratumoral, paracrine. ACTH, adrenocorticotropin hormone; AR, androgen receptor; DHEA, dihydroepiandrosterone; DHEAS, dihydroepiandrosteronesulphate; DHT, dihydrotestosterone; FSH, follicle-stimulating hormone; GnRH, gonadotropin-releasing hormone; LH, luteinizing hormone.

Group provided randomized, placebo-controlled data to support its use in preventing the development of metastatic disease. Disease progression had occurred by 10 years in $62 \%$ of men randomized to placebo vs. $32 \%$ randomized to orchiectomy, with no survival benefit noted using this approach. ${ }^{8}$ Additional benefits of surgical castration include the rapid palliation of symptoms, the elimination of patient compliance issues, as well as the cost/benefit ratio. ${ }^{9}$ The incidence of orchiectomy in the Western world has dropped dramatically, however, because of the irreversibility of this procedure and the potential to cause psychological distress.

Medical castration using GnRH agonists, such as leuprolide and goserelin, is currently the most prevalent method of androgen deprivation in the Western world. Treatment with these agents initially results in an elevation in endogenous LH and FSH from the hypothalamus in the first 1-2 weeks of therapy, with release of testosterone from the testes. It is for this reason that co-administration of androgen receptor antagonists (such as bicalutamide or nilutamide) prior to and for the first 2-4 weeks of therapy is recommended in metastatic prostate cancer, preventing an associated 'tumor flare'. Downregulation of pituitary gland receptors ensues which ultimately results in castration levels of testosterone $\left(<50 \mathrm{ng} \mathrm{dl}^{-1}\right)$ within approximately $4-8$ weeks. ${ }^{10}$

\section{Anti-androgens}

Anti-androgens are agents that bind directly to the androgen receptor, competitively inhibiting the binding of testosterone and DHT at this site. Testosterone levels are therefore normal or increased in men receiving these therapies, such that the side-effect profile may be more acceptable than with castration. The non-steroidal anti-androgens (bicalutamide, flutamide and nilutamide) may be used as an alternative to medical or surgical castration in advanced prostate cancer, although they are not the preferred treatment option. No study has directly compared these agents to each other. They may also be used in combination with $\mathrm{GnRH}$ analogs, a strategy known as combined androgen blockade $(\mathrm{CAB})$ which is discussed later. Steroidal antiandrogens, such as cyproterone acetate, are not generally recommended for use in management of prostate cancer patients in the United States of America, due to the suggestion of inferior outcomes with these agents $v s$. GnRH agonists. ${ }^{11}$

\section{INDICATIONS FOR USE OF ADT}

\section{Clinically localized and locally advanced prostate cancer}

Clinically localized prostate cancer is that which is confined to the prostate gland and the immediately surrounding tissues. Patients with up to T3a disease are often included in this category, although much of the prostate cancer literature includes only T1 and T2 tumors in this definition. Patients may be characterized as having a low, intermediate or high risk of disease recurrence, which helps to guide therapeutic strategies. $^{12,13}$ Patients with T2b/c disease, Gleason score 7 or a PSA level of 10-20 $\mathrm{ng} \mathrm{ml}^{-1}$ are deemed to have an intermediate risk of disease recurrence, and those with clinically localized T3a tumors, a Gleason score between 8 and 10 or a PSA level of $>20 \mathrm{ng} \mathrm{ml}^{-1}$ are

\section{Table 1 Classes of hormonal agents used to treat prostate cancer}

\begin{tabular}{|c|c|c|c|}
\hline Androgen deprivation therapy & Mechanism of action & Indications & Short-term adverse effects \\
\hline $\begin{array}{l}\text { GnRH agonists } \\
\text { Leuprolide } \\
\text { Goserelin } \\
\text { Triptorelin } \\
\text { Histrelin }\end{array}$ & $\begin{array}{l}\text { Downregulation of GnRH receptors in anterior } \\
\text { pituitary gland resulting in decreased } \mathrm{LH} \\
\text { and subsequent testosterone release }\end{array}$ & $\begin{array}{l}\text { Clinically localized and locally advanced } \\
\text { disease } \\
\text { Biochemically recurrent disease } \\
\text { Metastatic prostate cancer }\end{array}$ & $\begin{array}{l}\text { Testosterone surge requiring short-term } \\
\text { co-administration of androgen receptor } \\
\text { antagonists to prevent potential tumor } \\
\text { flare. Weight gain, hot flashes, sweats, } \\
\text { decreased libido, muscle weakness }\end{array}$ \\
\hline $\begin{array}{l}\text { GnRH antagonists } \\
\text { Degarelix }\end{array}$ & $\begin{array}{l}\text { Direct inhibition of } \mathrm{GnRH} \text { receptors } \\
\text { in anterior pituitary }\end{array}$ & $\begin{array}{l}\text { An alternative to } \mathrm{GnRH} \text { agonists in } \\
\text { metastatic prostate cancer }\end{array}$ & $\begin{array}{l}\text { Anaphylaxis, hot flashes, injection site } \\
\text { pain, weight gain and increased serum } \\
\text { transaminases }\end{array}$ \\
\hline $\begin{array}{l}\text { Anti-androgens } \\
\text { Bicalutamide } \\
\text { Nilutamide } \\
\text { Flutamide }\end{array}$ & $\begin{array}{l}\text { Direct binding to the androgen receptor, } \\
\text { competitively inhibiting the binding of } \\
\text { testosterone and DHT }\end{array}$ & $\begin{array}{l}\text { In combination with GnRH agonists as } \\
\text { combined androgen blockade for men } \\
\text { with advanced prostate cancer; second- } \\
\text { line therapy after progression on GnRH } \\
\text { agonist/antagonist monotherapy } \\
\text { (Alternative to GnRH agonists as first-line } \\
\text { therapy for advanced prostate cancer) }\end{array}$ & $\begin{array}{l}\text { Gynecomastia, breast pain, elevated liver } \\
\text { transaminases }\end{array}$ \\
\hline $\begin{array}{l}\text { CYP17 inhibitors } \\
\text { Ketoconazole } \\
\text { Aminogluthetimide } \\
\text { Abiraterone }\end{array}$ & $\begin{array}{l}\text { CYP17 inhibition in the adrenal gland } \\
\text { (and intratumorally) results in reduced } \\
\text { production of androgens from steroid } \\
\text { precursors }\end{array}$ & $\begin{array}{l}\text { Second-line therapy in advanced prostate } \\
\text { cancer; abiraterone is specifically } \\
\text { indicated in men who have progressed } \\
\text { after prior docetaxel chemotherapy }\end{array}$ & $\begin{array}{l}\text { Nausea and vomiting, adrenal } \\
\text { insufficiency requiring co-administration } \\
\text { of hydrocortisone, dermatologic effects, } \\
\text { elevated liver transaminases, } \\
\text { neuromuscular effects }\end{array}$ \\
\hline
\end{tabular}

Abbreviations: DHT, dihydrotestosterone; GnRH, gonadotropin-releasing hormone; LH, luteinizing hormone. 
deemed to have a high risk of disease recurrence. Locally advanced prostate cancer (stage $\mathrm{T} 3 \mathrm{~b} / 4$ ) is usually considered very high risk. ${ }^{14}$ The various indications for the use of ADT in these settings and the data supporting these indications have been reviewed previously ${ }^{15}$ and are described below (Table 2).

\section{ADT with surgery}

Neoadjuvant. In an effort to improve prostate cancer outcomes, a number of studies have examined the administration of neoadjuvant ADT prior to radical prostatectomy in men with early-stage prostate cancer. Many of these have randomized men to short-term ADT (3 months) vs. placebo with some demonstration of a decrease in tumor stage and grade. Unfortunately, these studies did not reveal an improvement in long-term outcomes such as a survival benefit. ${ }^{16-18}$ Other studies have evaluated longer duration of ADT. In a large, prospective phase III trial, the ability of 3 months vs. 8 months of neoadjuvant ADT to reduce PSA recurrence rates after radical prostatectomy was examined. Ongoing biochemical and pathological regression of prostate tumors occurred between 3 and 8 months of neoadjuvant ADT, suggesting that the optimal duration of neoadjuvant hormonal therapy is longer than 3 months. ${ }^{19}$ Despite demonstration of increased pathological complete remissions and clear surgical margins with longer duration of neoadjuvant ADT, studies have failed to detect significant improvements in survival. ${ }^{20} \mathrm{~A}$ recent phase II trial evaluated the benefit of neoadjuvant docetaxel for 3 cycles as well as 1 year of neoadjvuant $\mathrm{ADT}$ in patients with lymph node metastases scheduled to undergo radical prostatectomy. Eleven percent of evaluable patients progressed during therapy and $11 \%$ did not achieve a PSA level of $<1 \mathrm{ng} \mathrm{ml}^{-1}$ and were not offered primary surgical therapy. Surgery was completed in the remainder, and of those, $50 \%$ had no progression 1 year postoperatively (36\% of total population). Eight percent of patients had a pathological complete response. ${ }^{21}$ This neoadjuvant approach appeared feasible, but longer-term data are necessary to assess survival outcomes.

Adjuvant. The data supporting the use of adjuvant ADT after definitive surgical therapy for early-stage prostate cancer is limited. Ninety-eight men who were found to have pelvic lymph node involvement during radical prostatectomy were randomized to immediate ADT (GnRH agonist or bilateral orchiectomy) or observation until disease progression. With a median follow-up of 11.9 years, those assigned immediate ADT had a significant improvement in overall survival (OS) (hazard ratio $(\mathrm{HR})=1.84, P=0.04)$, prostate cancer-specific survival $(\mathrm{HR}=4.09$, $P=0.0004)$ and progression-free survival $(\mathrm{PFS})(\mathrm{HR}=3.42, P<0.0001)$ vs. those receiving deferred therapy. ${ }^{22}$ Therefore, the use of immediate ADT in lymph node-positive patients represents a reasonable strategy for these men, although observation until PSA progression may also be an alternative approach. Of note, most of the patients in the above study were treated in the pre-PSA era, and the applicability of these results in the present PSA era has been questioned. Most recently, the Southwest Oncology Group investigators reported the results in the ADT-alone control arm $(n=481)$ of the $\$ 9921$ study. This study randomly assigned 983 men with high-risk features at prostatectomy to receive adjuvant $\mathrm{ADT}$ alone (goserelin and bicalutamide for 2 years) or in combination with mitoxantrone chemotherapy. After a median follow-up of 4.4 years, the estimated 5-year biochemical failure-free survival was $92.5 \%$ and 5year OS was $95.9 \%$. The final results of the primary comparison are awaited, and these preliminary results (which indicate excellent survival in this cohort) may possibly support the administration of early adjuvant ADT to men with high-risk prostate cancer. ${ }^{23}$ However, it must be noted that the current standard of care for men with high-risk features on prostatectomy (extraprostatic extension, seminal vesicle invasion and positive surgical margins) is adjuvant radiation, which has been associated with improvements in biochemical relapse-free survival, metastasis-free survival and OS. ${ }^{24,25}$

\section{ADT with RT}

Clinically localized prostate cancer. GnRH agonists alone or combined with anti-androgens may be used prior to brachytherapy in an effort to reduce prostate volumes and minimize potential adverse effects associated with brachytherapy such as urinary symptoms in those with large prostates. In one study, patients with $\mathrm{T} 1 \mathrm{~b}-\mathrm{T} 2 \mathrm{c}$ prostate cancer received 3-6 months of a GnRH agonist prior to brachytherapy. The median decrease in prostate volume with ADT was 33\% among the 54 evaluable patients. Whether this approach results in an improvement in long-term tumor control remains to be determined. ${ }^{26}$ In another study, patients with bulky prostate tumors $(n=22)$ received 3 months of $\mathrm{CAB}$ prior to definitive RT and the median percentage of target volume reduction after $\mathrm{CAB}$ was 25\% (range: 3\%-52\%). This approach was felt to optimize the geometry of the target volume in relation to the adjacent normal tissue structures prior to RT. ${ }^{27}$ However, the use of hormone therapy to downsize the prostate for the purposes of external beam RT is no longer widely practiced.

The addition of ADT to primary external beam RT for clinically localized prostate cancer is well defined for patients with intermediateand high-risk disease by a number of randomized control trials.

A randomized trial was performed of primary RT with or without 6 months of ADT (GnRH agonist plus anti-androgen) in prostate cancer patients with T1b-T2b disease, a Gleason score of $\geqslant 7$, evidence of extraprostatic extension or a PSA level of $\geqslant 10 \mathrm{ng} \mathrm{ml}^{-1}(n=206)$. The majority of the patients in this trial, often referred to as the DanaFarber or D'Amico trial, had intermediate-risk disease with approximately $15 \%$ having high-risk disease. Patients randomized to the combination arm had a significantly higher survival $(P=0.04)$, lower prostate cancer-specific mortality $(P=0.02)$ and higher survival free of salvage $\operatorname{ADT}(P=0.002)$ after a median follow-up of 4.5 years. ${ }^{28}$

The Radiation Therapy Oncology Group (RTOG) 94-08 trial evaluated a shorter duration of ADT (also GnRH agonist plus anti-androgen) in patients with T1b-T2b disease and a PSA level of $\leqslant 20 \mathrm{ng} \mathrm{ml}^{-1}$ $(n=1979)$. The addition of 4 months of ADT commencing 2 months prior to RT was associated with an improved OS of $62 \%$ at 10 years $v s$. $57 \%$ for those treated with RT alone $(P=0.03)$. In a post hoc subgroup analysis, the benefit was only seen for intermediate-risk patients, not low-risk ones. ${ }^{29}$

The optimal timing of ADT in relation to RT in clinically localized prostate cancer has been examined in the RTOG 9413 trial $(n=1323)$. This four-arm trial was designed to test two hypotheses: $\mathrm{CAB}$ and wholepelvic radiotherapy (WPRT) followed by a prostate boost improves PFS by $\geqslant 10 \%$ compared with $\mathrm{CAB}$ and prostate-only $\mathrm{RT}$; and neoadjuvant hormonal therapy followed by concurrent $\mathrm{CAB}$ and RT improves PFS by $\geqslant 10 \%$ compared with RT followed by adjuvant hormonal therapy. There was no difference in PFS between the neoadjuvant and adjuvant arms. An unexpected interaction was found between the timing of hormonal therapy and radiation field size for this patient population. When neoadjuvant hormonal therapy was used in conjunction with RT, WPRT yielded a better PFS than prostate-only RT, and in addition, neoadjuvant hormonal therapy plus WPRT resulted in better OS than WPRT adjuvant hormonal therapy. ${ }^{30}$

Finally, in a phase III Canadian study which randomized patients with clinically localized prostate cancer to 3 months $v s .8$ months of combined ADT before definitive RT $(n=378)$, no significant differences were observed between the arms with respect to local, distant 
Table 2 Select phase III trials supporting the use of ADT in prostate cancer

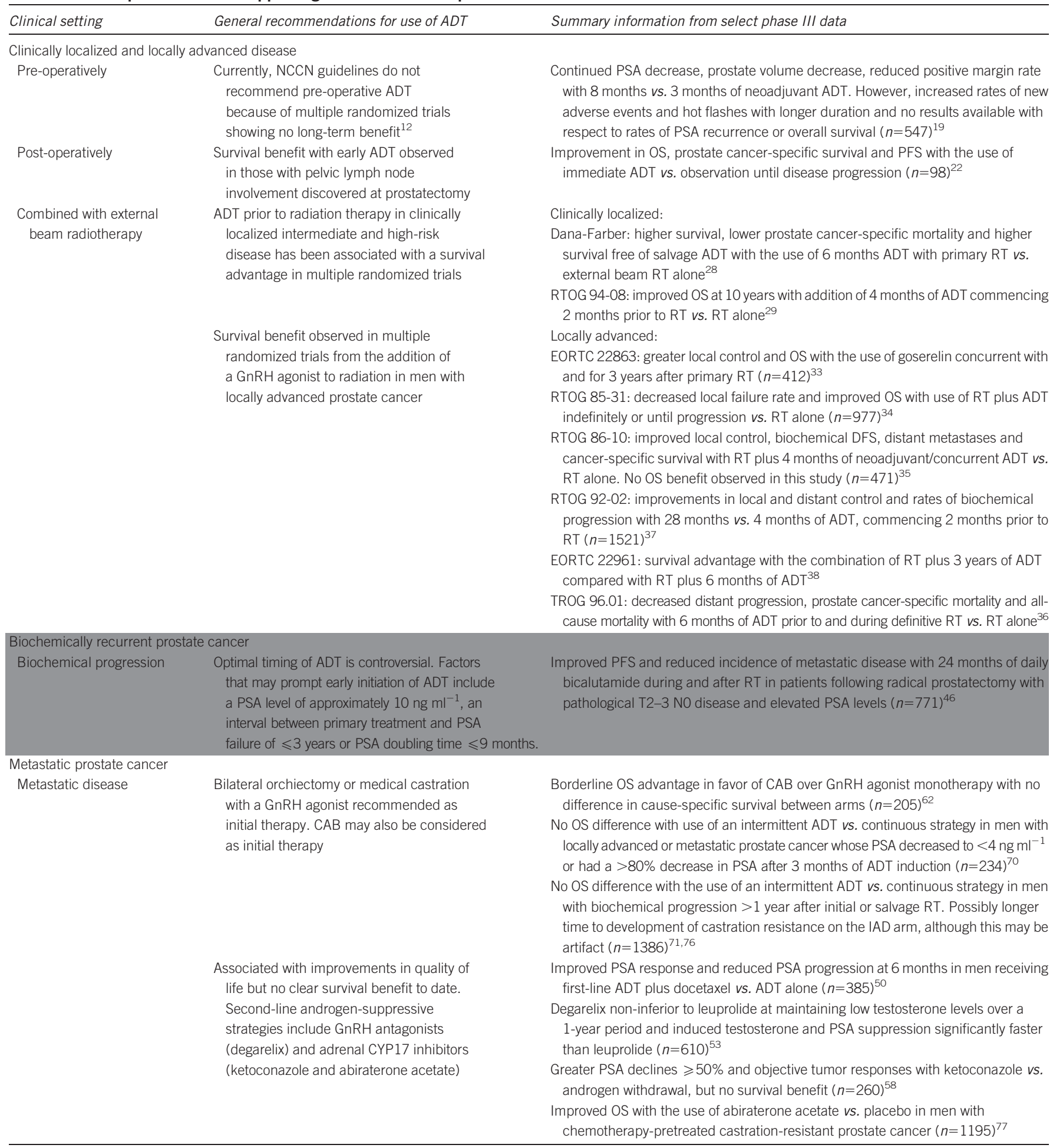

Abbreviations: ADT, androgen deprivation therapy; CAB, combined androgen blockade; NCCN, the national comprehensive cancer network; OS, overall survival; PFS, progression-free survival; PSA, prostate-specific antigen; RT, radiation therapy.

or biochemical failure rates, or indeed in survival. There was a suggestion of benefit for patients with high-risk disease who accounted for $57 \%$ of the study population. ${ }^{31}$

In summary, based on the available data and our collective clinical experience, the authors generally advocate the use of 4-6 months of
ADT (GnRH agonist with or without anti-androgen) for men with intermediate-risk localized prostate cancer undergoing definitive external beam RT, but not for men with low-risk localized prostate cancer. In the latter population, ADT not only does not improve survival, but it may even be harmful, and this practice should be avoided. 
High-risk and locally advanced prostate cancer. A number of large randomized trials have demonstrated a survival advantage with the addition of a $\mathrm{GnRH}$ agonist to radiation in men with locally advanced prostate cancer.

A prospective phase III randomized trial coordinated by the European Organization for Research and Treatment of Cancer (EORTC) compared primary external irradiation to primary external irradiation plus goserelin $(n=412)$ in patients with T3 or T4 disease (EORTC 22863). Goserelin was commenced on the first day of radiation and continued for 3 years, as well as flutamide during the first month of treatment. With a median follow-up of 66 months, local control and survival were significantly higher in the goserelin arm. OS at 5 years was $78 \%$ in the combined-treatment group and $62 \%$ in the RT alone group $(P=0.0002) .^{32,33}$

The RTOG Trial 85-31 study randomized patients with clinical T3 or N1 disease to definitive RT alone or in combination with ADT indefinitely or until progression $(n=977)$. Patients in the radiationalone arm received $\mathrm{ADT}$ at progression. At 10 years, the local failure rate $(23 \%$ vs. $38 \%, P<0.0001)$ and $\mathrm{OS}(49 \%$ vs. $39 \%, P=0.002)$ favored the combination arm vs. RT alone. Patients with a Gleason score of 7-10 obtained the greatest survival benefit. ${ }^{34}$

Shorter durations of ADT in conjunction with definitive RT have also been evaluated. Patients with bulky T2-T4 disease were randomized to RT alone or RT plus 4 months of neoadjuvant/concurrent ADT $(n=471)$ in RTOG $86-10$. With 8 years of follow-up, significant improvements in local control ( $42 \%$ vs. 30\%, $P=0.016)$, biochemical DFS ( $24 \%$ vs. $10 \%, P<0.0001$ ), distant metastases (34\% vs. $45 \%$, $P=0.04)$ and cancer-specific mortality ( $23 \%$ vs. $31 \%, P=0.05)$ were observed in the combination arm; however, no OS benefit was demonstrated with this approach. ${ }^{35}$

In order to help define the question of optimal duration of ADT in this setting, a three-arm trial (TROG 96.01) of RT alone, or RT with 3 or 6 months of ADT commencing 2 or 5 months prior to definitive RT respectively for localized and locally advanced prostate cancer enrolled 818 men. The median follow-up was 10.6 years and $84 \%$ of patients had high-risk disease. The benefits of 6 months of ADT prior to and during definitive RT ( $n=802$ eligible for analysis) included decreased distant progression $(\mathrm{HR}=0.49, P=0.001)$, prostate cancer-specific mortality $(\mathrm{HR}=0.49, P=0.0008)$ and all-cause mortality $(\mathrm{HR}=0.63$, $P=0.0008$ ) when compared with RT alone. Three months of ADT had no effect on these parameters, although it did prolong time to PSA progression, time to local progression and event-free survival. ${ }^{36}$

Two trials have compared an even longer duration of ADT with short duration of ADT in patients with locally advanced and generally high-risk disease. RTOG 9202 randomized patients to 4 months vs. 28 months of ADT, commencing 2 months prior to RT. Subgroup analyses revealed an OS benefit with longer duration of therapy only for men with Gleason scores of 8-10 (5-year OS 81\% vs. 71\%, P=0.044). In the population as a whole, longer duration resulted in improvements in local and distant control as well as rates of biochemical progression. ${ }^{37}$ Similarly, the combination of RT plus 6 months of androgen suppression was associated with inferior survival, as compared with RT plus the longer duration of 3 years of androgen suppression in 1113 men with locally advanced prostate cancer enrolled in an EORTC 22961 trial. $^{38}$

In summary, based on the available data and clinical experience, the authors generally recommend the use of 24-36 months of ADT (GnRH agonist with or without anti-androgen) for men with high-risk localized or locally advanced prostate cancer who undergo primary external beam RT. However, this decision must be balanced against the known long-term toxicities of ADT, especially in men with known risk factors for metabolic syndrome, cardiovascular disease and osteoporosis.

\section{ADT used alone}

The use of ADT alone for men with clinically localized prostate cancer who may wish to avoid primary surgery or RT is generally not recommended due to concerns for an adverse impact on prostate cancer outcomes and quality of life (QoL) with this approach. ${ }^{14}$ In an analysis of 19271 men with prostate cancer in the Surveillance, Epidemiology and End Results (SEER) database linked to Medicare, the use of primary ADT was associated with an increased risk of prostate cancerspecific mortality compared to observation $(\mathrm{HR}=1.17,95 \%$ confidence interval (CI): 1.03-1.33), and there was no difference in overall mortality $(\mathrm{HR}=1.00,95 \% \mathrm{CI}: 0.96-1.05))^{39}$ As this was an observational study, it is a strong possibility that these results were due to confounding by indication bias. In a randomized phase III trial (EORTC 30846), men receiving early vs. deferred ADT who did not undergo radical prostatectomy did not appear to benefit from the early approach $(n=302)$. At a median follow-up of 9.6 years, $62.9 \%$ had died, including $76 \%$ from prostate cancer. For those randomized to early vs. deferred ADT, the HR for survival on delayed vs. immediate treatment was 1.23 , indicating a $23 \%$ non-significant trend in favor of early treatment. ${ }^{40}$

For men with clinical T3 disease, definitive primary therapy with either radical prostatectomy or RT with $\mathrm{ADT}$ is the generally recommended approach. The benefit of definitive RT over ADT alone was investigated in a study which randomized patients with high-risk disease to ADT plus RT vs. ADT alone ( 3 months of CAB followed by flutamide until progression or death). ${ }^{41}$ The 10 -year overall mortality was lower in the ADT plus RT arm $(29.6 \%$ vs. $39.4 \%, P=0.004)$.

\section{Biochemical progression}

Biochemical recurrence of prostate cancer is defined as a progressively increasing PSA level after primary RT or surgical therapy or both, in the absence of radiographic evidence of metastatic disease. The exact definition varies depending on the primary therapy received. For example, for men who have had a prostatectomy, biochemical progression may be defined as any increase in the PSA level or a PSA level of $\geqslant 0.2$ or $0.4 \mathrm{ng} \mathrm{ml}^{-1}$ on a minimum of three consecutive evaluations. ${ }^{42}$ Whether the rising PSA reflects local or distant recurrence of disease is difficult to assess, although the latter is more likely with higher PSA values.

In a retrospective review of a large surgical series $(n=1997)$ of men at a single institution undergoing radical prostatectomy for clinically localized prostate cancer, 315 men developed biochemical PSA elevation. Of those who did not receive early ADT $(n=304), 34 \%$ developed metastatic disease with a median time to metastases of 8 years from the time of PSA recurrence. In addition, this study identified factors that predicted the risk of developing metastatic disease: these included time to biochemical progression $(P<0.001)$, Gleason score $(P<0.001)$ and PSA doubling time $(P<0.001) .{ }^{43}$ An updated analysis of this same cohort with a longer follow-up established that the median metastasis-free survival in men with biochemically recurrent prostate cancer after prostatectomy was 10 years, even in the absence of salvage radiation or hormonal therapies. ${ }^{44}$ This prolonged time to metastatic progression has been confirmed in an independent patient population, ${ }^{45}$ and suggests that only patients with high-risk features (Gleason score $>7$, PSA doubling time $\leqslant 9$ months) should be treated with immediate ADT in this setting.

While many men with non-metastatic biochemical recurrence have often been treated with early ADT in this setting, prospective data 
supporting this approach is lacking and there is no direct evidence to date that this strategy delays the onset of radiographically evident metastases or improves survival. Further discussion about the controversy relating to early $v s$. deferred use of ADT, including the risk/ benefit ratio, is included in a subsequent section. In clinical practice, factors that may prompt early initiation of ADT include a PSA level of approximately $10 \mathrm{ng} \mathrm{ml}^{-1}$, an interval between primary treatment and PSA failure $\leqslant 2-3$ years or a PSA doubling time $\leqslant 9$ months.

In addition, if the disease is believed to be localized, then consideration should be given for available local treatment options, such as the use of salvage RT after previous prostatectomy. Recently, the effect of ADT plus bicalutamide during and after RT on freedom from progression and incidence of metastatic disease in patients following radical prostatectomy with pathological T2-3 N0 disease and elevated PSA levels was reported. In this phase III study, the addition of 24 months of daily bicalutamide during and after RT significantly improved freedom from progression and reduced the incidence of metastatic disease without adding significantly to the toxicity of RT. A longer follow-up is necessary to determine if any survival benefit is obtained with this strategy. ${ }^{46}$

A number of phase III trials have evaluated the efficacy of continuous administration of ADT compared to intermittent ADT, as discussed later in this review.

In conclusion, it is the opinion of the authors that early ADT should be avoided in men with biochemical recurrence with low risk of metastatic progression (i.e., Gleason sum $\leqslant 6$; PSA doubling time $>9$ months). In these patients, ADT should be initiated only upon radiographic evidence of distant osseous or visceral metastases. In men with high-risk PSA-recurrent disease (i.e., Gleason sum >7; PSA doubling time $\leqslant 9$ months), early use of ADT before the first metastatic occurrence may be a reasonable option. In the authors' view, such patients should ideally be treated with intermittent ADT (as discussed in a subsequent section). However, in men that develop documented radiographic metastatic disease (even in the absence of symptoms), the authors generally advocate initiation of continuous ADT in that setting.

\section{Metastatic disease}

Current guidelines recommend bilateral orchiectomy or medical castration with a $\mathrm{GnRH}$ agonist as initial therapy for metastatic prostate cancer. ${ }^{47}$ These treatment options are associated with improvements in symptom control; however, no clear survival advantage has been demonstrated with the use of ADT in this setting. ${ }^{2}$ Because of an immediate increase in testosterone with medical castration, coadministration of an anti-androgen is recommended for 2-4 weeks to counteract the testosterone surge which may result in a flare reaction and bone pain. Also, in patients receiving medical castration, continuation of the GnRH agonist agent even beyond progression is recommended. Therefore, even in patients who eventually go on to receive subsequent therapies such as chemotherapy, maintenance of castrate levels of serum testosterone is the recommended approach. By consensus, adequate castration is defined as a serum testosterone level of $<50 \mathrm{ng} \mathrm{dl}^{-1}$, although recent evidence suggests that more potent testosterone suppression may provide additional clinical benefits.

An initial large randomized control trial in men with advanced prostate cancer compared orchiectomy $v s$. no therapy. There was no survival difference between the arms. However, men in the control arm were treated with androgen ablation after 9 years, such that this trial may be viewed as a comparison of early $v$ s. deferred ADT. ${ }^{8,48}$

In a more contemporary study, patients with locally advanced prostate cancer or those with asymptomatic metastases $(n=938)$ were randomized to immediate ADT (GnRH analog or orchiectomy) vs. deferred therapy until progressive or symptomatic disease. The development of progressive metastatic disease $(P<0.001)$ and metastatic pain $(P<0.001)$ occurred more rapidly in those patients randomized to treatment deferral. Pathological fracture, spinal cord compression, ureteric obstruction and the development of non-skeletal metastases were also twice as common in the deferred arm. Death was more frequent in the deferred arm $(n=361)$ than the immediate therapy arm $(n=328, P=0.02)$ with 257 and 203 deaths attributed to prostate cancer respectively $(P=0.001)$. However, these study results have been criticized as many patients in the deferred arm died before ever commencing ADT. ${ }^{2}$

A meta-analysis of randomized controlled trials $(n=6600)$ was performed to compare GnRH agonists against orchiectomy and to compare anti-androgens against surgical/medical castration. GnRH agonist use was found to be equivalent to orchiectomy in terms of survival, irrespective of the agent used. Monotherapy with a nonsteroidal anti-androgen was associated with a slightly lower survival overall, with results trending towards significance. ${ }^{11}$ Monotherapy with a steroidal anti-androgen also resulted in inferior time to progression in a randomized trial comparing it to goserelin, such that anti-androgens are not recommended as initial monotherapy for advanced prostate cancer. ${ }^{49}$

In an effort to improve on the benefit observed with initial ADT in metastatic prostate cancer, a European phase III multicenter trial compared $\mathrm{ADT}$ alone to $\mathrm{ADT}$ plus docetaxel chemotherapy in the first-line setting $(n=385)$. The addition of 3-weekly docetaxel to ADT significantly improved PSA response (defined as $>50 \%$ PSA decline) and significantly reduced PSA progression at 6 months. OS results, the primary objective of this study, are not yet available and are eagerly awaited. ${ }^{50}$ A similar phase III study is currently being conducted in the United States of America by the Eastern Cooperative Study Group (study E3805), which randomizes patients with newly diagnosed metastatic prostate cancer to receive ADT alone or in combination with 6 cycles of 3-weekly docetaxel; the primary end point of this study is OS.

\section{ALTERNATIVE FORMS OF ANDROGEN DEPRIVATION}

The use of ADT for men with advanced prostate cancer invariably results in eventual disease progression despite castrate levels of serum testosterone (a condition termed castration-resistant prostate cancer (CRPC)), with the duration of response to first-line hormonal therapy being approximately 2-3 years. Withdrawal of anti-androgen in the setting of $\mathrm{CAB}$ may result in a subsequent PSA decrease in 10\%-35\% of patients. ${ }^{51}$ Alternative androgen-suppressive strategies include GnRH antagonists, and adrenal androgen synthesis inhibitors.

GnRH antagonists, such as degarelix (and abarelix), are potential therapeutic alternatives to the more standard GnRH agonists described above. Androgen concentrations are reduced by these agents by blocking the GnRH receptor directly and as such they do not cause an LH surge and the unwanted initial testosterone increase associated with GnRH analogs. Anti-androgen supplementation prior to and during initiation of treatment is therefore not required with this class of drugs. Abarelix was the first $\mathrm{GnRH}$ antagonist to be approved by the US Food and Drug Administration (FDA), but was withdrawn from the US market due to an unacceptable rate of systemic allergic reactions. Subsequently, the FDA approved degarelix for use in advanced prostate cancer in 2008 at a dose of $80 \mathrm{mg}$ monthly subcutaneously after a 240 -mg loading dose. ${ }^{52}$ In a phase III trial randomizing 610 patients with prostate cancer (any stage) to degarelix or leuprolide with a primary end point of suppression of testosterone to $\leqslant 0.5 \mathrm{ng} \mathrm{ml}^{-1}$, degarelix was non-inferior to leuprolide at maintaining low testosterone levels over a 1-year period and induced testosterone 
and PSA suppression significantly faster than leuprolide. ${ }^{53}$ An updated analysis reported that of the 504 patients who completed the 1-year trial, 384 chose to continue in an extension study in which those on leuprolide were rerandomized to degarelix $240 / 80 \mathrm{mg}$ or $240 / 160 \mathrm{mg}$. During the first year of treatment, the risk of PSA PFS was found to be significantly lower with degarelix $240 / 80 \mathrm{mg} v$ s. leuprolide $(P=0.05)$. At a median follow-up of 27.5 months, the hazard rate of PSA PFS significantly decreased in leuprolide patients crossing over to degarelix compared with before the crossover $(P=0.003) .{ }^{54}$ Short-term adverse effects of this agent include hot flashes, injection site pain, weight gain and increased serum transaminases. ${ }^{55}$

Cytochrome P450 inhibitors have also been employed in treating advanced prostate cancer as second-line hormonal therapy and beyond, as these enzymes are necessary for the synthesis of androgens. These agents include ketoconazole, aminogluthetimide and abiraterone acetate. Ketoconazole, an imidazole antifungal agent, inhibits adrenal androgen synthesis by functioning as a non-selective inhibitor of CYP $17 .{ }^{56}$ Ketoconazole may also have a direct cytotoxic effect on prostate cancer cells in preclinical models. ${ }^{57}$ In a phase III trial comparing anti-androgen withdrawal alone $(n=132)$ vs. anti-androgen withdrawal plus ketoconazole $(n=128)$, PSA declines of $\geqslant 50 \%$ were observed in $11 \%$ vs. $27 \%$ of patients, and objective tumor responses were seen in $2 \%$ vs. $20 \%$ of men with measurable disease, respectively. ${ }^{58}$ However, median survival did not differ between the groups (16.7 months vs.15.3 months respectively). Because of the side effects of this agent, including nausea and vomiting in approximately half of all patients, it is often a difficult drug to tolerate. In addition, adrenal insufficiency can ensue with this therapy such that patients usually require concurrent hydrocortisone supplementation.

Abiraterone acetate is a novel oral selective androgen biosynthesis inhibitor that selectively and potently blocks the action of CYP17 in the testes and the adrenal glands, resulting in complete androgen suppression. In addition, recent evidence suggests that prostate tumors themselves are able to synthesize endogenous androgens, which are also blocked by abiraterone. Following the presentation of results from a pivotal placebo-controlled phase III trial in men with chemotherapy-pretreated metastatic CRPC, FDA recently approved abiraterone for use in combination with prednisone for the treatment of patients with metastatic CRPC who have received prior docetaxel. This decision was based on data from a phase III randomized, placebocontrolled, multicenter trial in 1195 patients with metastatic CRPC. An OS analysis conducted after 775 events demonstrated a median OS of 14.8 months $v s .10 .9$ months in the abiraterone acetate $(n=797)$ and placebo-containing arms $(n=398)$, respectively $(\mathrm{HR}=0.65, P<0.001)$, providing an additional therapeutic option for men with advanced prostate cancer previously treated with chemotherapy. Secondary mineralocorticoid-related adverse events were more commonly observed in the abiraterone arm and included fluid retention (31\%), hypokalemia (17\%), hypertension (10\%) and cardiac disease (13\%). ${ }^{59}$ In a preplanned analysis of this trial, circulating tumor cells as part of a biomarker panel were evaluated as a surrogate biomarker for OS. To this end, conversion from an unfavorable circulating tumor cell count ( $\geqslant 5$ cells) to a favorable circulating tumor cell count $(<5$ cells) as early as 4 weeks after initiation of abiraterone was predictive of OS in this phase III study. ${ }^{60}$ However, the most appropriate use of abiraterone remains to be defined, and the optimal combination and sequencing of this agent with other hormonal and non-hormonal therapies for prostate cancer will hopefully be elucidated in the next several years. ${ }^{61}$ In addition, it is currently unknown whether abiraterone should be continued beyond disease progression. Although current treatment paradigms suggest that abiraterone should be stopped when men develop cancer progression, the notion of persistent and maximal androgen suppression seems like a rational strategy and should be tested in clinical trials.

Finally, new and more potent anti-androgens have also entered the treatment arena. MVD3100, an agent that functions both as an androgen receptor antagonist and also prevents translocation of the androgen receptor from the cytoplasm into the nucleus (where it mediates transcriptional activation), is currently being investigated in phase III trials in men with metastatic CRPC, both in the pre- and post-chemotherapy settings.

\section{CONTROVERSIES RELATING TO ADT FOR ADVANCED PROSTATE CANCER}

Monotherapy vs. combined androgen blockade

Although bilateral orchiectomy or medical castration with a $\mathrm{GnRH}$ agonists are the recommended initial therapy for men with metastatic prostate cancer, the use of $\mathrm{CAB}$ may also be considered and discussed at the time of treatment decision-making. ${ }^{47}$ Bicalutamide is the agent of choice of non-steroidal anti-androgen based on data from a randomized trial which compared $\mathrm{CAB}$ with bicalutamide to a $\mathrm{GnRH}$ analog alone. $^{62}$ Long-term follow-up of this phase III trial indicated a borderline significant $\mathrm{OS}$ advantage in favor of $\mathrm{CAB}$ over $\mathrm{GnRH}$ agonist monotherapy $(\mathrm{HR}=0.78, P=0.05)$. However, the difference in causespecific survival between the groups was not significant. Adverse events were similar in both arms. A number of meta-analyses have also indicated a possible modest improvement in survival with use of CAB in this setting. The largest of these was a collaborative meta-analysis of 27 randomized trials incorporating 8275 men with metastatic $(88 \%)$ or locally advanced ( $12 \%$ ) prostate cancer randomized to CAB or surgical/ medical castration alone. ${ }^{63}$ In the overall analysis, 5-year survival was 25.4\% with $\mathrm{CAB}$ vs. $23.6 \%$ with castration alone, a statistically nonsignificant difference. Results from those patients receiving nilutamide and flutamide appeared slightly more favorable than the overall population with 5 -year survival of $27.6 \%$ for $\mathrm{CAB}$ and $24.7 \%$ for castration alone $(P=0.005)$. Results of studies incorporating bicalutamide were not yet available for this meta-analysis. Other meta-analyses have indicated an increased rate of adverse events with use of $\mathrm{CAB}$, in particular excess GI toxicity and ophthalmologic adverse events. ${ }^{64}$ The overall potential benefits and risks of $\mathrm{CAB}$ should therefore be considered when discussing the role of $\mathrm{CAB}$ with patients. Bicalutamide does appear to be better tolerated than other agents in the same class. ${ }^{62}$

\section{Immediate $v s$. deferred hormone therapy}

Men with symptomatic prostate cancer should generally have ADT initiated without delay. There are a number of clinical scenarios, however, where controversy exists over the decision to initiate early ADT (i.e., immediately upon PSA progression) or defer therapy to a later timepoint (e.g., at the time of metastasis, or upon symptomatic progression). These areas of uncertainly relate especially to asymptomatic men with a rising PSA only after definitive primary therapy, men with radiographic but asymptomatic metastases, and those with pathologic node-positive disease. As mentioned previously, prospective data are lacking relating to this issue in patients with biochemical progression of PSA. Ongoing trials aim to shed light on this setting and include the Canadian Early vs. Late Androgen Ablation Therapy trial and the Australian and New Zealand Timing of Androgen Deprivation trial. Until then, concerns exist regarding the risk-benefit ratio of early initiation of therapy $v s$. an active surveillance strategy due to a lack of evidence to support a survival benefit as well as the risk of bothersome and potentially serious adverse events 
(which will be discussed by other authors in this issue of the journal). Close surveillance of these patients enables the evaluation of symptoms or signs of metastatic disease both clinically and with annual bone imaging as well as determination of the PSA doubling time. ${ }^{65}$ Testosterone levels and QoL are maintained in the absence of ADT, and ADT may be initiated upon symptomatic progression or overt radiographic metastases. In addition, expert guidelines recommend considering clinical trial enrolment for these patients. ${ }^{47}$

The majority of data relating to the timing of ADT initiation comes from the advanced setting where ADT is initiated shortly after diagnosis of prostate cancer $v s$. at time of progressive disease. A number of randomized-controlled trials have been published comparing early vs. deferred ADT in men with localized or locally advanced disease. ${ }^{66}$ The SAK 08/88 trial was closed early due to an inability to accrue the predefined patient numbers ( $n=197$ of 360 anticipated). Patients were randomly assigned to receive either immediate or deferred orchiectomy at the time of symptomatic progression. There was a trend towards longer cancer-specific survival in the immediate group but there was no difference in OS between the two groups $(P=0.96)$. Interestingly, $42 \%$ of patients in the deferred therapy arm never required any prostate cancer therapy. ${ }^{66}$ In the larger EORTC 30891 study $(n=985)$, men with localized prostate cancer not suitable for local curative treatment were treated with immediate or deferred ADT. Immediate ADT resulted in a modest but statistically significant increase in OS but no significant difference in prostate cancer mortality or symptom-free survival $(\mathrm{HR}=1.25 \text {, non-inferiority } P>0.1)^{67}$ The Early Prostate Cancer Program trial randomized 8113 men with localized or locally advanced prostate cancer (all M0) who had received standard care (radical radiation, radical prostatectomy or watchful waiting) to oral bicalutamide daily $v s$. placebo. ${ }^{68}$ At a median follow-up of 7.4 years, the addition of bicalutamide did not result in a PFS benefit. However, in locally advanced disease, bicalutamide significantly improved PFS, irrespective of the primary therapy used.

Because of the variability in the survival benefit observed with early $\mathrm{ADT}$ in these settings, the appropriate management of these patients remains controversial. Loblaw et al. ${ }^{47}$ combined the randomized data for these asymptomatic patient trials and reported that early ADT was associated with a $17 \%$ reduction in relative risk for prostate cancer-specific mortality, a $15 \%$ decrease in relative risk for non-prostate cancerspecific mortality, but no OS advantage. In practice, ADT is sometimes initiated early based on the presence of a number of prognostic factors including age, Gleason score, absolute PSA value and PSA doubling time, factors which were not incorporated into many of these trials. ${ }^{69}$

By contrast, a survival benefit with early ADT has been observed in men found to have pelvic lymph node involvement after radical prostatectomy and pelvic lymphadenectomy. With a median follow-up of 11.9 years, those assigned immediate ADT had a significant improvement in OS $(\mathrm{HR}=1.84, P=0.04)$, prostate cancer-specific survival, $P=0.0004)$ and PFS $(3.42, P<0.0001) v s$. those assigned deferred therapy. ${ }^{22}$ Some of the caveats with this trial have been discussed above.

\section{Intermittent $v s$. continuous hormone therapy}

Intermittent androgen deprivation (IAD) refers to cyclic administration of hormonal therapy. ADT may be administered until a predefined PSA response is observed, such as a PSA level of $<4 \mathrm{ng} \mathrm{ml}^{-1}$ or a $>80 \%$ decrease in the PSA level, ${ }^{70}$ and then may be stopped and restarted once the PSA begins to rise again. The clear potential benefit of this approach is that testosterone levels rise off therapy, the adverse events associated with $\mathrm{ADT}$ are minimized and QoL is improved. However, there have been questions about whether this approach is as efficacious as continuous $\mathrm{ADT}$ in relation to prostate cancer outcomes. ${ }^{70} \mathrm{~A}$ number of phase III trials testing this question have recently been reported, while several others are ongoing. The South European Oncology Group $(n=626)$ examined whether the intermittent therapeutic approach was associated with a shorter time to progression. After a 3-month ADT induction period, patients with locally advanced or metastatic prostate cancer whose PSA decreased to $<4 \mathrm{ng} \mathrm{ml}^{-1}$ or had a $>80 \%$ decrease in PSA were randomized to IAD or continued ADT. There were 127 patients from the IAD arm and 107 patients from the continuous arm who progressed $(\mathrm{HR}=0.81, P=0.11)$. There was no difference in OS as the $10 \%$ increase in the number of cancer deaths in the IAD arm (106 vs. 84) was offset by more cardiovascular deaths in the continuous arm (52 vs. 41). The adverse effect profile was better in the $\mathrm{IAD}$ arm, with more men in this arm reporting better sexual function, although QoL was reported as similar between the arms. ${ }^{70}$

Another large intergroup trial randomized 1386 men with biochemical progression $>1$ year after initial or salvage radical RT to IAD or continuous therapy to test for non-inferiority of IAS with respect to OS. IAD was prescribed for 8 months in each cycle, and was then stopped with subsequent re-initiation of ADT when PSA reached $10 \mathrm{ng} \mathrm{ml}^{-1}$ off therapy. At a median follow-up of 6.9 years, median OS was 8.8 years vs. 9.1 years for the IAD and continuous arms, respectively $(\mathrm{HR}=1.02, P=0.009)$. More disease-related (122 vs. 97) and fewer unrelated (134 vs. 146) deaths occurred in the IAD arm. In addition, the time to development of castration resistance was statistically significantly longer on the IAD $\operatorname{arm}(\mathrm{HR}=0.80$, $P=0.024)$. The only difference in adverse events between the arms in this study was a reduced incidence of hot flashes in the patients receiving IAD. ${ }^{71}$ Ongoing phase III trials will attempt to clarify the same question in men with metastatic prostate cancer.

Based on the results of these two large randomized trials, it appears that IAD may be non-inferior to a continuous therapeutic approach in terms of prostate cancer progression and survival, and is definitely more cost-effective. Unanswered questions include whether a certain population of patients will benefit most from this approach, the optimal schedule that should be employed, and the PSA level at which treatment should be discontinued and then reinitiated. In addition, whether management of the cardiovascular effects of ADT may negate the survival equivalence between the IAD and continuous $\mathrm{ADT}$ is unclear.

\section{PATTERNS OF USE OF ADT}

Prescribing patterns relating to the use of ADT for various indications have varied since their introduction. Increased use of ADT in the 1990s was found to occur across all stages and histologic grades of prostate carcinoma, and was the greatest in patients aged 80 years or greater. ${ }^{72} \mathrm{~A}$ subsequent study using SEER-Medicare data from 1991 to 2005 found prevalent ADT use to increase through the 1990s, peak in 2000 and fall in $2005 .{ }^{73}$ During a period of relative stability in use between 2000 and $2002,44.8 \%$ of men with incident prostate cancer were prescribed ADT during the first year after diagnosis: the most common indications being as an adjuvant with RT (15\% of cases) and as a primary therapy (14\%). Predictors of ADT use in a lower-risk setting were older age, higher stage and grade, and elevated PSA levels. ${ }^{73}$ Alarmingly, these changing patterns have been shown to be associated with alterations in reimbursement policies. ${ }^{74}$ Policy changes may impact the financial incentives for physicians associated with prescription of ADT and may influence the decision to use ADT in cases of uncertain benefit. ${ }^{75}$ The potential impact of the introduction of the Medicare Modernization Act, which led to reductions in reimbursement for ADT for prostate cancer, was examined using SEER-Medicare data from 2003 to 2005. 
This Act cut the reimbursements for GnRH agonists moderately in 2004 (about 15\%) but quite drastically in 2005 (an additional 35\%) for a total reduction of 50\% between 2003 and 2005. In this analysis, the use of $\mathrm{ADT}$ as primary therapy for men with localized cancers of a low-tomoderate grade was deemed inappropriate; however, it was considered appropriate as adjuvant therapy with RT for men with locally advanced cancers. The use of ADT was deemed discretionary for men receiving primary or adjuvant therapy for localized, high-grade tumors. The rate of 'inappropriate' use of ADT declined significantly from $38.7 \%$ in 2003 to $25.7 \%$ in 2005 . No decrease in use was observed in the 'appropriate' use of adjuvant ADT. There was a significant decline in use in 2005 with discretionary use, but not in $2004 .^{74}$ These changes in prescribing practice appear to be closely related to reductions in reimbursement for $\mathrm{GnRH}$ agonists during this time.

\section{CONCLUSION}

ADT plays a valuable role in a number of settings for men with prostate cancer. Its use results in volume reduction of primary tumors prior to primary surgical or RT, provides a possible survival benefit in the adjuvant setting for men with pelvic lymph node involvement after primary surgical therapy, and improves survival when added to external beam RT for men with intermediate- and high-risk clinically localized prostate cancer or locally advance prostate cancer. No clear survival advantage has been observed with the use of ADT in men with metastatic disease, but improvements in bone pain and cancer complications are frequently observed, and this remains the first-line therapy of choice for men with metastatic prostate cancer nevertheless. Ongoing trials aim to further elucidate the role of ADT where controversy exists. Second-line therapeutic options are available for men with CRPC and a promising addition to the armamentarium is abiraterone acetate, providing an OS benefit in this setting and implying that even castration-resistant disease remains androgen driven. Other strategies for men with CRPC include the use of taxane-based chemotherapies, and bisphosphonates and palliative radiation or systemic radioisotopes where bony pain is present. In addition, a novel immunotherapy (sipuleucel-T) has been shown to provide a survival advantage in men with asymptomatic metastatic CRPC, and has gained FDA approval.

A growing concern amongst the prostate cancer community is the short- and long-term side effect profile of ADT. Bothersome and frequently reported side effects include loss of libido, erectile dysfunction and hot flashes. Bone density loss as well as an increased risk of cardiovascular disease and mortality due to the metabolic effects of ADT needs to be taken into consideration, when evaluating the risk-benefit ratio of a therapeutic strategy incorporating ADT. These considerations will form the central theme of other articles in this issue of the journal. Finally, economic analyses using data from well-designed randomized trials should also help define the role of ADT in patients with prostate cancer.

\section{AUTHOR CONTRIBUTIONS}

RMC wrote the draft of the manuscript under the supervision of ESA and MAC, who also performed critical revision of the manuscript and approved the final version. All others contributed the preparation of the manuscript.

\section{COMPETING FINANCIAL INTERESTS}

The authors declared no conflicts of interest.

1 http://www.seer.cancer.gov/statfacts/html/prost.html. Accessed online June 7th 2011.
2 Immediate versus deferred treatment for advanced prostatic cancer: initial results of the Medical Research Council Trial. The Medical Research Council Prostate Cancer Working Party Investigators Group. Br J Urol 1997; 79: 235-46.

3 Krsmanovic LZ, Hu L, Leung PK, Feng H, Catt KJ. The hypothalamic GnRH pulse generator: multiple regulatory mechanisms. Trends Endocrinol Metab 2009; 20 402-8.

4 Dufau ML, Catt KJ. Gonadotropin receptors and regulation of steroidogenesis in the testis and ovary. Vitam Horm 1978; 36: 461-592.

5 Means AR, Fakunding JL, Huckins C, Tindall DJ, Vitale R. Follicle-stimulating hormone, the Sertoli cell, and spermatogenesis. Recent Prog Horm Res 1976; 32: 477-527.

6 Federman DD. The biology of human sex differences. NEng/ J Med 2006; 354: 1507 14.

7 Huggins C, Hodges CV. Studies on prostatic cancer: I. The effect of castration, of estrogen and of androgen injection on serum phosphatases in metastatic carcinoma of the prostate. 1941. J Urol 2002; 168: 9-12.

8 Byar DP. Proceedings: The Veterans Administration Cooperative Urological Research Group's studies of cancer of the prostate. Cancer 1973; 32: 1126-30.

9 Loblaw DA, Mendelson DS, Talcott JA, Virgo KS, Somerfield MR et al. American Society of Clinical Oncology recommendations for the initial hormonal management of androgen-sensitive metastatic, recurrent, or progressive prostate cancer. J Clin Oncol 2004; 22: 2927-41

10 Limonta P, Montagnani Marelli M, Moretti RM. LHRH analogues as anticancer agents: pituitary and extrapituitary sites of action. Expert Opin Investig Drugs 2001; 10: 709-20.

11 Seidenfeld J, Samson DJ, Hasselblad V, Aronson N, Albertsen PC et al. Single-therapy androgen suppression in men with advanced prostate cancer: a systematic review and meta-analysis. Ann Intern Med 2000; 132: 566-77.

12 http://www.nccn.org/professionals/physician_gls/pdf/prostate.pdf. Accessed online April 22nd 2011.

13 Mohler J, Bahnson RR, Boston B, Busby JE, D'Amico A et al. NCCN clinical practice guidelines in oncology: prostate cancer. J Natl Compr Canc Netw 2010; 8: 162-200.

14 D'Amico AV, Whittington R, Malkowicz SB, Schultz D, Blank K et al. Biochemical outcome after radical prostatectomy, external beam radiation therapy, or interstitial radiation therapy for clinically localized prostate cancer. JAMA 1998; 280: 969-74.

15 Antonarakis ES, Blackford AL, Garrett-Mayer E, Eisenberger MA. Survival in men with nonmetastatic prostate cancer treated with hormone therapy: a quantitative systematic review. J Clin Oncol 2007; 25: 4998-5008.

16 Aus G, Abrahamsson PA, Ahlgren G, Hugosson J, Lundberg S et al. Three-month neoadjuvant hormonal therapy before radical prostatectomy: a 7-year follow-up of a randomized controlled trial. BJU Int 2002; 90: 561-6.

17 Soloway MS, Sharifi R, Wajsman Z, McLeod D, Wood DP Jr et al. Randomized prospective study comparing radical prostatectomy alone versus radical prostatectomy preceded by androgen blockade in clinical stage B2 (T2bNxMO) prostate cancer. The Lupron Depot Neoadjuvant Prostate Cancer Study Group. J Urol 1995; 154: 424-8.

18 Schulman CC, Debruyne FM, Forster G, Selvaggi FP, Zlotta AR et al. 4-year follow-up results of a European prospective randomized study on neoadjuvant hormonal therapy prior to radical prostatectomy in T2-3N0M0 prostate cancer. European Study Group on Neoadjuvant Treatment of Prostate Cancer. Eur Urol 2000; 38: 706-13.

19 Gleave ME, Goldenberg SL, Chin JL, Warner J, Saad F et al. Randomized comparative study of 3 versus 8-month neoadjuvant hormonal therapy before radical prostatectomy: biochemical and pathological effects. J Urol 2001; 166: 500-6; discussion 506-7.

20 Selli C, Montironi R, Bono A, Pagano F, Zattoni F et al. Effects of complete androgen blockade for 12 and 24 weeks on the pathological stage and resection margin status of prostate cancer. J Clin Pathol 2002; 55: 508-13.

21 Pagliaro LC, Zurita AJ, Araujo JC, Ward JF, Davis JW et al. Presurgical docetaxel (Doc) and androgen deprivation therapy (ADT) in lymph node-positive prostate cancer (PCa). J Clin Oncol 2011; 29 (Suppl): abstract 4619.

22 Messing EM, Manola J, Yao J, Kiernan M, Crawford D et al. Immediate versus deferred androgen deprivation treatment in patients with node-positive prostate cancer after radical prostatectomy and pelvic lymphadenectomy. Lancet Oncol 2006: 7: 472-9

23 Dorff TB, Flaig TW, Tangen CM, Hussain MH, Swanson GP et al. Adjuvant androgen deprivation for high-risk prostate cancer after radical prostatectomy: SWOG S9921 study. J Clin Oncol 2011; 29: 2040-5.

24 Bolla M, van Poppel H, Tombal B. 10-year results of adjuvant radiotherapy after radical prostatectomy in pT3NO prostate cancer (EORTC 22991) (abstract). Int J Radiat Biol Phys 2010; 78: s29.

25 Thompson IM, Tangen CM, Paradelo J, Lucia MS, Miller G et al. Adjuvant radiotherapy for pathological T3NOMO prostate cancer significantly reduces risk of metastases and improves survival: long-term followup of a randomized clinical trial. J Urol2009; 181: 956-62.

26 Whittington R, Broderick GA, Arger P, Malkowicz SB, Epperson RD et al. The effect of androgen deprivation on the early changes in prostate volume following transperineal ultrasound guided interstitial therapy for localized carcinoma of the prostate. Int J Radiat Oncol Biol Phys 1999; 44: 1107-10.

27 Zelefsky MJ, Leibel SA, Burman CM, Kutcher GJ, Harrison A et al. Neoadjuvant hormonal therapy improves the therapeutic ratio in patients with bulky prostatic cancer treated with three-dimensional conformal radiation therapy. Int J Radiat Oncol Biol Phys 1994; 29: 755-61.

28 D'Amico AV, Manola J, Loffredo M, Renshaw AA, DellaCroce A et al. 6-month androgen suppression plus radiation therapy vs radiation therapy alone for patients with 
clinically localized prostate cancer: a randomized controlled trial. JAMA 2004; 292 : $821-7$

29 Jones CU, Hunt D, McGowan DG, Amin MB, Chetner MP et al. Radiotherapy and short-term androgen deprivation for localized prostate cancer. N Engl J Med 2011; 365: 107-18.

30 Lawton CA, DeSilvio M, Roach M 3rd, Uhl V, Kirsch R et al. An update of the phase III trial comparing whole pelvic to prostate only radiotherapy and neoadjuvant to adjuvant total androgen suppression: updated analysis of RTOG 94-13, with emphasis on unexpected hormone/radiation interactions. Int J Radiat Oncol Biol Phys 2007; 69: 646-55.

31 Crook J, Ludgate C, Malone S, Lim J, Perry G et al. Report of a multicenter Canadian phase III randomized trial of 3 months vs. 8 months neoadjuvant androgen deprivation before standard-dose radiotherapy for clinically localized prostate cancer. Int J Radiat Oncol Biol Phys 2004; 60: 15-23.

32 Bolla M, Gonzalez D, Warde P, Dubois JB, Mirimanoff RO et al. Improved survival in patients with locally advanced prostate cancer treated with radiotherapy and goserelin. N Engl J Med 1997; 337: 295-300.

33 Bolla M, Collette L, Blank L, Warde P, Dubois JB et al. Long-term results with immediate androgen suppression and external irradiation in patients with locally advanced prostate cancer (an EORTC study): a phase III randomised trial. Lancet 2002; 360: 103-6.

34 Pilepich MV, Winter K, Lawton CA, Krisch RE, Wolkov HB et al. Androgen suppression adjuvant to definitive radiotherapy in prostate carcinoma-long-term results of phase III RTOG 85-31. Int J Radiat Oncol Biol Phys 2005; 61: 1285-90.

35 Pilepich MV, Winter K, John MJ, Mesic JB, Sause W et al. Phase III radiation therapy oncology group (RTOG) trial 86-10 of androgen deprivation adjuvant to definitive radiotherapy in locally advanced carcinoma of the prostate. Int J Radiat Oncol Biol Phys 2001; 50: 1243-52.

36 Denham JW, Steigler A, Lamb DS, Joseph D, Turner S et al. Short-term neoadjuvant androgen deprivation and radiotherapy for locally advanced prostate cancer: 10-year data from the TROG 96.01 randomised trial. Lancet Oncol 2011; 12: 451-9.

37 Horwitz EM, Bae K, Hanks GE, Porter A, Grignon DJ et al. Ten-year follow-up of radiation therapy oncology group protocol 92-02: a phase III trial of the duration of elective androgen deprivation in locally advanced prostate cancer. J Clin Oncol 2008; 26: 2497-504.

38 Bolla M, de Reijke TM, van Tienhoven G, van den Bergh AC, Oddens J et al. Duration of androgen suppression in the treatment of prostate cancer. N Engl J Med 2009; 360 . 2516-27.

39 Lu-Yao GL, Albertsen PC, Moore DF, Shih W, Lin Y et al. Survival following primary androgen deprivation therapy among men with localized prostate cancer. JAMA2008; 300: 173-81.

40 Schroder FH, Kurth KH, Fossa SD, Hoekstra W, Karthaus PP et al. Early versus delayed endocrine treatment of pN1-3 M0 prostate cancer without local treatment of the primary tumor: results of European Organisation for the Research and Treatment of Cancer 30846-a phase III study. J Urol 2004; 172: 923-7.

41 Widmark A, Klepp O, Solberg A, Damber JE, Angelsen A et al. Endocrine treatment, with or without radiotherapy, in locally advanced prostate cancer (SPCG-7/SFUO-3): an open randomised phase III trial. Lancet 2009; 373: 301-8.

42 Amling CL, Bergstralh EJ, Blute ML, Slezak JM, Zincke H. Defining prostate specific antigen progression after radical prostatectomy: what is the most appropriate cut point? J Urol 2001; 165: 1146-51.

43 Pound CR, Partin AW, Eisenberger MA, Chan DW, Pearson JD et al. Natural history of progression after PSA elevation following radical prostatectomy. JAMA 1999; 281: 1591-7

44 Antonarakis ES, Feng Z, Trock BJ, Humphreys EB, Carducci MA et al. The natural history of metastatic progression in men with prostate-specific antigen recurrence after radical prostatectomy: long-term follow-up. BJU Int 2012; 109: 32-9.

45 Antonarakis ES, Chen Y, Elsamanoudi SI, Brassell SA, da Rocha MV et al. Long-term overall survival and metastasis-free survival for men with prostate-specific antigenrecurrent prostate cancer after prostatectomy: analysis of the Center for Prostate Disease Research National Database. BJU Int 2011; 108: 378-85.

46 Shipley WU, Hunt D, Lukka HR, Major P, Heney NM et al. Initial report of RTOG 9601, a phase III trial in prostate cancer: effect of anti-androgen therapy (AAT) with bicalutamide during and after radiation therapy (RT) on freedom from progression and incidence of metastatic disease in patients following radical prostatectomy (RP) with pT2-3,N0 disease and elevated PSA levels. J Clin Oncol 2011; 29 (Suppl 7): abstract 1.

47 Loblaw DA, Virgo KS, Nam R, Somerfield MR, Ben-Josef E et al. Initial hormonal management of androgen-sensitive metastatic, recurrent, or progressive prostate cancer: 2006 update of an American Society of Clinical Oncology practice guideline. J Clin Oncol 2007; 25: 1596-605.

48 Treatment and survival of patients with cancer of the prostate. The Veterans Administration Co-operative Urological Research Group. Surg Gynecol Obstet 1967; 124: 1011-7.

49 Thorpe SC, Azmatullah S, Fellows GJ, Gingell JC, O'Boyle PJ. A prospective, randomised study to compare goserelin acetate (Zoladex) versus cyproterone acetate (Cyprostat) versus a combination of the two in the treatment of metastatic prostatic carcinoma. Eur Urol 1996; 29: 47-54.

50 Gravis G, Fizazi K, Joly F, Oudard S, Priou F et al. PSA response and early PSA progression evaluated in patients randomized in a phase III trial comparing androgen-deprivation therapy (ADT) plus docetaxel versus ADT alone in hormonenaive metastatic prostate cancer (GETUG-AFU 15/0403). J Clin Oncol 2011; 29 (Suppl 7): abstract 10
51 Scher HI, Kelly WK. Flutamide withdrawal syndrome: its impact on clinical trials in hormone-refractory prostate cancer. J Clin Oncol 1993; 11: 1566-72.

52 Ferring Pharmaceuticals Inc. Firmagon prescribing information, December 2008. Available from: http://www.accessdata.fda.gov/drugsatfda.docs/label/2008/022201lbl. pdf. Accessed online December 23rd 2011.

53 Klotz L, Boccon-Gibod L, Shore ND, Andreou C, Persson BE et al. The efficacy and safety of degarelix: a 12-month, comparative, randomized, open-label, parallel-group phase III study in patients with prostate cancer. BJU Int 2008; 102: 1531-8.

54 Shore ND, Moul JW, Crawford E, van der Meulen E, Olesen T et al. Prostate-specific antigen (PSA) progression-free survival (PFS): a comparison of degarelix versus leuprolide in patients with prostate cancer. J Clin Oncol 2011; 29 (Suppl 7): abstract 12.

55 Steinberg M. Degarelix: a gonadotropin-releasing hormone antagonist for the management of prostate cancer. Clin Ther 2009; 31: 2312-31.

56 Pont A, Williams PL, Azhar S, Reitz RE, Bochra C et al. Ketoconazole blocks testosterone synthesis. Arch Intern Med 1982; 142: 2137-40.

57 Eichenberger T, Trachtenberg J, Toor P, Keating A. Ketoconazole: a possible direct cytotoxic effect on prostate carcinoma cells. J Urol 1989; 141: 190-1.

58 Small EJ, Halabi S, Dawson NA, Stadler WM, Rini BI et al. Antiandrogen withdrawal alone or in combination with ketoconazole in androgen-independent prostate cancer patients: a phase III trial (CALGB 9583). J Clin Oncol 2004; 22: 1025-33.

59 de Bono JS, Logothetis CJ, Molina A, Fizazi K, North S et al. Abiraterone and increased survival in metastatic prostate cancer. N Engl J Med 2011; 364: 1995-2005.

60 Scher HI, Heller G, Molina A, Kheoh TS, Attard G et al. Evaluation of circulating tumor cell (CTC) enumeration as an efficacy response biomarker of overall survival (OS) in metastatic castration-resistant prostate cancer (mCRPC): planned final analysis (FA) of COU-AA-301, a randomized double-blind, placebo-controlled phase III study of abiraterone acetate (AA) plus low-dose prednisone $(P)$ post docetaxel. J Clin Oncol 2011; 29 (Suppl): abstract LBA4517.

61 Antonarakis ES, Eisenberger MA. Expanding treatment options for metastatic prostate cancer. N Engl J Med 2011; 364: 2055-8.

62 Akaza H, Hinotsu S, Usami M, Arai Y, Kanetake $\mathrm{H}$ et al. Combined androgen blockade with bicalutamide for advanced prostate cancer: long-term follow-up of a phase 3, double-blind, randomized study for survival. Cancer 2009; 115: 3437-45.

63 Maximum androgen blockade in advanced prostate cancer: an overview of the randomised trials. Prostate Cancer Trialists' Collaborative Group. Lancet 2000; 355: 1491-8.

64 Schmitt B, Wilt TJ, Schellhammer PF, DeMasi V, Sartor O et al. Combined androgen blockade with nonsteroidal antiandrogens for advanced prostate cancer: a systematic review. Urology 2001; 57: 727-32.

65 Walczak JR, Carducci MA. Prostate cancer: a practical approach to current management of recurrent disease. Mayo Clin Proc 2007; 82: 243-9.

66 Studer UE, Hauri D, Hanselmann S, Chollet D, Leisinger HJ et al. Immediate versus deferred hormonal treatment for patients with prostate cancer who are not suitable for curative local treatment: results of the randomized trial SAKK 08/88. J Clin Oncol 2004; 22: 4109-18.

67 Studer UE, Whelan P, Albrecht W, Casselman J, de Reijke T et al. Immediate or deferred androgen deprivation for patients with prostate cancer not suitable for local treatment with curative intent: European Organisation for Research and Treatment of Cancer (EORTC) Trial 30891. J Clin Oncol 2006; 24: 1868-76.

68 McLeod DG, Iversen P, See WA, Morris T, Armstrong J et al. Bicalutamide 150 mg plus standard care vs standard care alone for early prostate cancer. BJU Int 2006; 97: 247-54.

69 Quon H, Loblaw DA. Androgen deprivation therapy for prostate cancer-review of indications in 2010. Curr Oncol 2010; 17 (Suppl 2): S38-44.

70 Calais da Silva FE, Bono AV, Whelan P, Brausi M, Marques Queimadelos A et al. Intermittent androgen deprivation for locally advanced and metastatic prostate cancer: results from a randomised phase 3 study of the South European Uroncological Group. Eur Urol 2009; 55: 1269-77.

71 Crook JM, O'Callaghan CJ, Ding K, Duncan G, Dearnaley DP et al. A phase III randomized trial of intermittent versus continuous androgen suppression for PSA progression after radical therapy (NCIC CTG PR.7/SWOG JPR.7/CTSU JPR.7/UK Intercontinental Trial CRUKE/01/013). J Clin Oncol 2011; 29 (Suppl): abstract 4514

72 Shahinian VB, Kuo YF, Freeman JL, Orihuela E, Goodwin JS. Increasing use of gonadotropin-releasing hormone agonists for the treatment of localized prostate carcinoma. Cancer 2005; 103: 1615-24.

73 Gilbert SM, Kuo YF, Shahinian VB. Prevalent and incident use of androgen deprivation therapy among men with prostate cancer in the United States. Urol Oncol 2011; 29: 647-53.

74 Shahinian VB, Kuo YF, Gilbert SM. Reimbursement policy and androgen-deprivation therapy for prostate cancer. N Engl J Med 2010; 363: 1822-32.

75 Shahinian VB, Kuo YF, Freeman JL, Orihuela E, Goodwin JS. Characteristics of urologists predict the use of androgen deprivation therapy for prostate cancer. J Clin Oncol 2007; 25: 5359-65.

76 Klotz L, O'Callaghan CJ, Ding K, Dearnaley DP, Higano CS et al. A phase III randomized trial comparing intermittent versus continuous androgen suppression for patients with PSA progression after radical therapy: NCIC CTG PR.7/SWOG JPR.7/CTSU JPR.7/UK Intercontinental Trial CRUKE/01/013. J Clin Oncol 2011; 29 (Suppl 7): abstract 3.

77 Scher HI, Logothetis C, Molina A, Goodman OB, Sternberg CN et al. Improved survival outcomes in clinically relevant patient subgroups from COU-AA-301, a phase III study of abiraterone acetate $(A A)$ plus prednisone $(P)$ in patients with metastatic castrationresistant prostate cancer (mCRPC) progressing after docetaxel-based chemotherapy. $J$ Clin Oncol 2011; 29 (Suppl 7): abstract 4. 